\title{
Effect of geometrical parameters on heat transfer and pressure drop characteristics of plate fin and tube heat exchangers
}

\author{
Aytunç Erek ${ }^{a}$, Barış Özerdem ${ }^{b, *}$, Levent Bilir ${ }^{b}$, Zafer İlken ${ }^{b}$ \\ ${ }^{a}$ Department of Mechanical Engineering, Dokuz Eylül University, Bornova, 35100 İzmir, Turkey \\ ${ }^{\mathrm{b}}$ Department of Mechanical Engineering, Izmir Institute of Technology, Urla, 35430 İzmir, Turkey
}

Received 19 July 2004; accepted 13 December 2004

Available online 2 March 2005

\begin{abstract}
In this study, the influences of the changes in fin geometry on heat transfer and pressure drop of a plate fin and tube heat exchanger are investigated, numerically. A computational fluid dynamics (CFD) program called Fluent is used in the analysis. The segment of one tenth of fin is used in the modeling, due to symmetrical condition. The results of heat transfer, static, and total pressure drop values of ten different fins are tabulated and the normalized values of them are, also, given for the comparison of the models. The distance between fins is found to have a considerable effect on pressure drop. It is observed that placing the fin tube at downstream region affects heat transfer positively. Another important result of the study is that increasing ellipticity of the fin tube increases the heat transfer while it, also, results in an important reduction in pressure drop.
\end{abstract}

(C) 2005 Elsevier Ltd. All rights reserved.

Keywords: Plate fin; Heat exchanger; Numerical modeling; Heat transfer; Pressure drop

\footnotetext{
${ }^{*}$ Corresponding author. Tel.: +90 232750 6519; fax: +90 2327506505 .

E-mail address: barisozerdem@iyte.edu.tr (B. Özerdem).
} 


\begin{tabular}{|ll}
\hline Nomenclature \\
$a$ & Bigger radius of elliptical tube $(\mathrm{mm})$ \\
$b$ & Smaller radius of elliptical tube $(\mathrm{mm})$ \\
$f$ & Fanning friction factor \\
$L$ & Fin height $(\mathrm{mm})$ \\
$L_{1}$ & Fin tube center location $(\mathrm{mm})$ \\
$\mathrm{Nu}$ & Average Nusselt number \\
$\mathrm{Pr}$ & Prandtl number \\
$Q$ & Heat transfer rate $(\mathrm{W})$ \\
$\mathrm{Re}$ & Reynolds number \\
$t$ & Fin tube thickness $(\mathrm{mm})$ \\
$t_{1}$ & Fin thickness (mm)
\end{tabular}

\section{Introduction}

Fin and tube type heat exchangers have many application areas in the field of thermal engineering. There are various fin patterns such as plate, louver, convex-louver, and wavy. Among these patterns, plate fin configuration is the most popular fin pattern in heat exchanger applications, owing to its simplicity, rigidity, and economical impact. Typical tube geometries used in heat exchangers are circular and elliptical.

Plate fin and tube heat exchangers have been investigated by many researchers due to their widespread usage. First, Shepherd [1] analyzed plate fin and circular tube heat exchangers. Then, Schulemberg [2] conducted similar study for plate fin and elliptic tubes. Saboya and Sparrow [3-5] used the naphthalene sublimation technique in order to obtain local and overall heat and mass transfer coefficients for different configurations, experimentally. Webb [6] reported that elliptical tubes have better performance than circular tubes. Determination of local and overall heat transfer coefficients is conducted by Rosman et al. [7]. Rocha et al. [8] analyzed plate fin heat exchangers with circular and elliptical tubes and determined heat transfer coefficients, experimentally. Kundu and Das [9] determined optimum dimensions of a plate fin and tube heat exchanger for both rectangular and equilateral triangular array of tubes. Abu Madi et al. [10] examined the effect of geometrical variations of flat and corrugated fins and the results are correlated in terms of Colburn and friction factors. Romero-Méndez et al. [11] investigated the effect of the distance between two fins on the total heat transfer rate and pressure drop for a single row fin and tube heat exchanger by using flow visualization and numerical computation techniques. Wang and Chi [12] determined the effect of tube rows, fin pitch, and tube diameter on heat transfer and pressure drop of a plate fin and tube heat exchanger, experimentally. Wang et al. [13] developed correlations of the Colburn and friction factors which are valid for plate fin and tube heat exchangers. Saboya and Saboya [14] determined the average heat transfer coefficient for plate fin and elliptic tube heat exchangers by using naphthalene sublimation technique. The same sublimation technique is used for plate fin heat exchangers with circular tubes by Kim and Song [15]. Torikoshi et al. [16] investigated a plain fin and tube heat exchanger, numerically. 


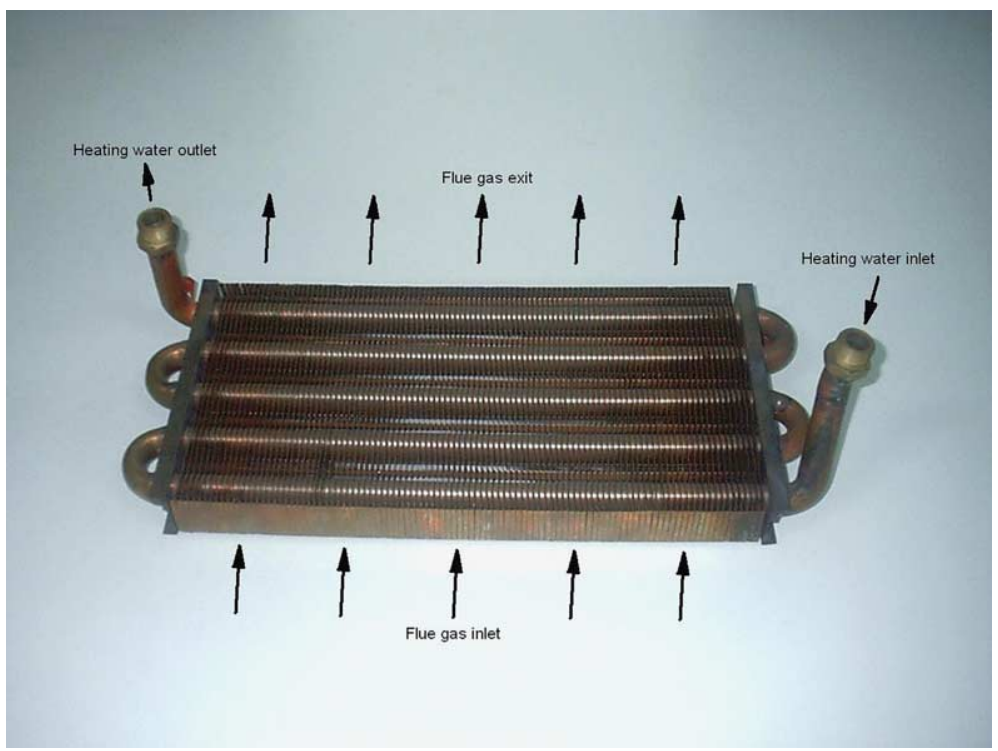

Fig. 1. View of an analyzed plate fin and tube heat exchanger.

The investigations mentioned above have determined effective factors on heat transfer and pressure drop across a heat exchanger. However, the effect of geometrical parameters, except fin spacing and fin pitch, had not been analyzed numerically, so far. In the present study, a plate fin type heat exchanger with one row tube configuration is analyzed for different geometrical parameters by using a numerical computation technique. Namely, the effects of the distance between two fins, tube center location, fin height, tube thickness, and tube ellipticity on heat transfer and pressure drop across the heat exchanger are investigated, numerically. Fig. 1 shows a typical plate fin and tube heat exchanger of a heater used in the analyses.

\section{Definition and modeling of the problem}

\subsection{Model description}

A CFD software, Fluent, is used for the numerical analysis. The studied model, which is shown in Fig. 2, consists of two fins with half fin thickness, fin tube, tubecover, and flue gas between the fins. Due to the symmetry, only one tenth segment of the fin is modeled. The model is created and meshed by using Gambit software.

The volume representing the flue gas which is passing through the gap between two fins is extended in $y$ directions at both inlet and exit sides, since this configuration enables more accurate boundary condition application. Four hexahedral finite volume elements along the thickness of the half fin and twenty of the same elements along the distance between two fins are used. As a result, approximately 4,00,000 hexahedral meshes are generated for each model. Then, the created 


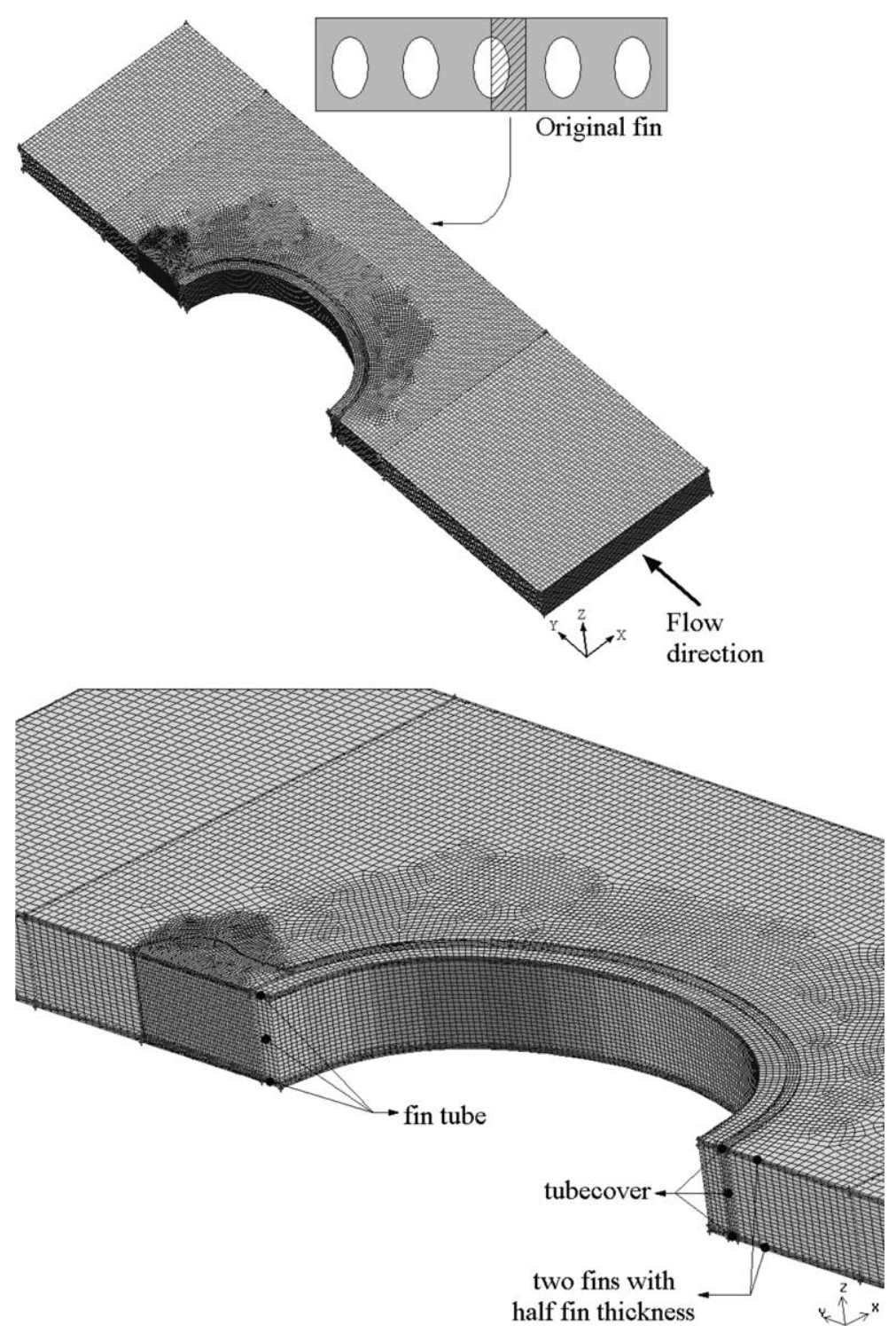

Fig. 2. Original fin and the segment used in the modeling.

model in Gambit software is exported to the Fluent software in which boundary conditions and material properties are defined.

\subsection{Boundary conditions}

Mass flow inlet boundary condition is defined for bottom surface, since flue gas enters from that cross section. The mass flow rate used in all of the models is $1.904 \times 10^{-5} \mathrm{~kg} / \mathrm{s}$. Temperature 
value of the flue gas at the inlet is, also, defined for this surface as $1500 \mathrm{~K}$. These values are taken from the application results. Symmetrical boundary conditions have been applied to the side, front and back surfaces of the model due to the symmetry. The flue gas is exhausted from the top side of the heat exchanger. So, the outflow boundary condition is given to this surface. For the other surfaces, wall boundary conditions have been applied. The convection coefficients between the water flowing inside the tubes and the inner wall are calculated by using the Gnielinski correlation shown in Eq. (1) for fully developed turbulent forced convection through a duct [17].

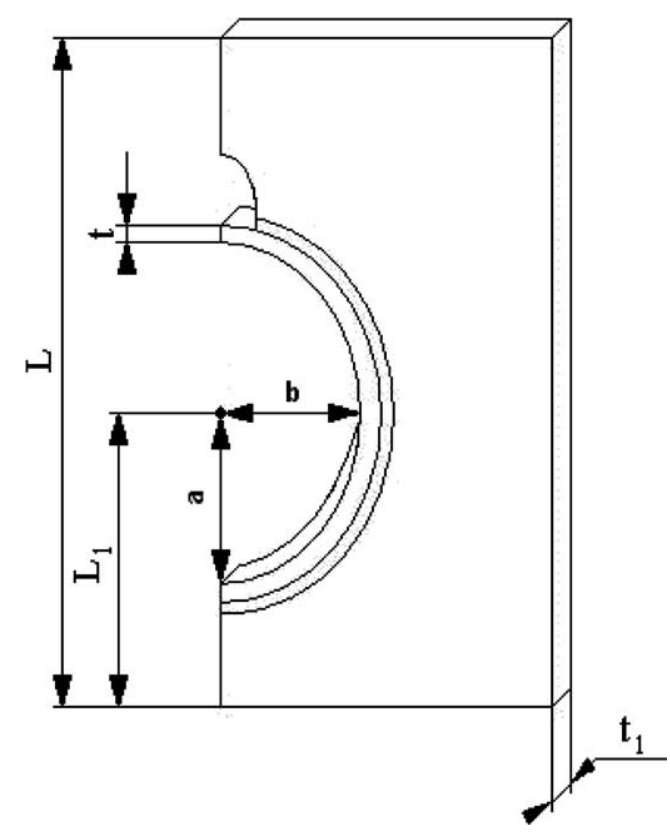

Fig. 3. Schematic view of fin dimensions.

Table 1

Dimensions of the models

\begin{tabular}{llllll}
\hline Model type & $L(\mathrm{~mm})$ & $L_{1}(\mathrm{~mm})$ & $t(\mathrm{~mm})$ & $t_{1}(\mathrm{~mm})$ & Ellipticity $b / a$ \\
\hline $\mathrm{a}$ & 35 & 15.5 & 0.8 & 0.4 & 0.7345 \\
$\mathrm{~b}$ & 35 & 15.5 & 0.8 & 0.3 & 0.7345 \\
$\mathrm{c}$ & 35 & 18.5 & 0.8 & 0.4 & 0.7345 \\
$\mathrm{~d}$ & 35 & 12.5 & 0.8 & 0.4 & 0.7345 \\
$\mathrm{e}$ & 38 & 18.5 & 0.8 & 0.4 & 0.7345 \\
$\mathrm{f}$ & 38 & 15.5 & 0.8 & 0.4 & 0.7345 \\
$\mathrm{~g}$ & 35 & 15.5 & 0.6 & 0.4 & 0.7345 \\
$\mathrm{~h}$ & 35 & 15.5 & 1.2 & 0.4 & 0.7345 \\
$\mathrm{i}$ & 35 & 18.5 & 0.8 & 0.4 & 0.4064 \\
$\mathrm{j}$ & 35 & 15.1 & 0.8 & 0.4 & 1 \\
\hline
\end{tabular}




$$
\mathrm{Nu}=\frac{(f / 2)(\mathrm{Re}-1000) \operatorname{Pr}}{1+12.7(f / 2)^{\frac{1}{2}}\left(\operatorname{Pr}^{\frac{2}{3}}-1\right)}
$$

where, $f=(1.58 \ln \mathrm{Re}-3.28)^{-2}$.
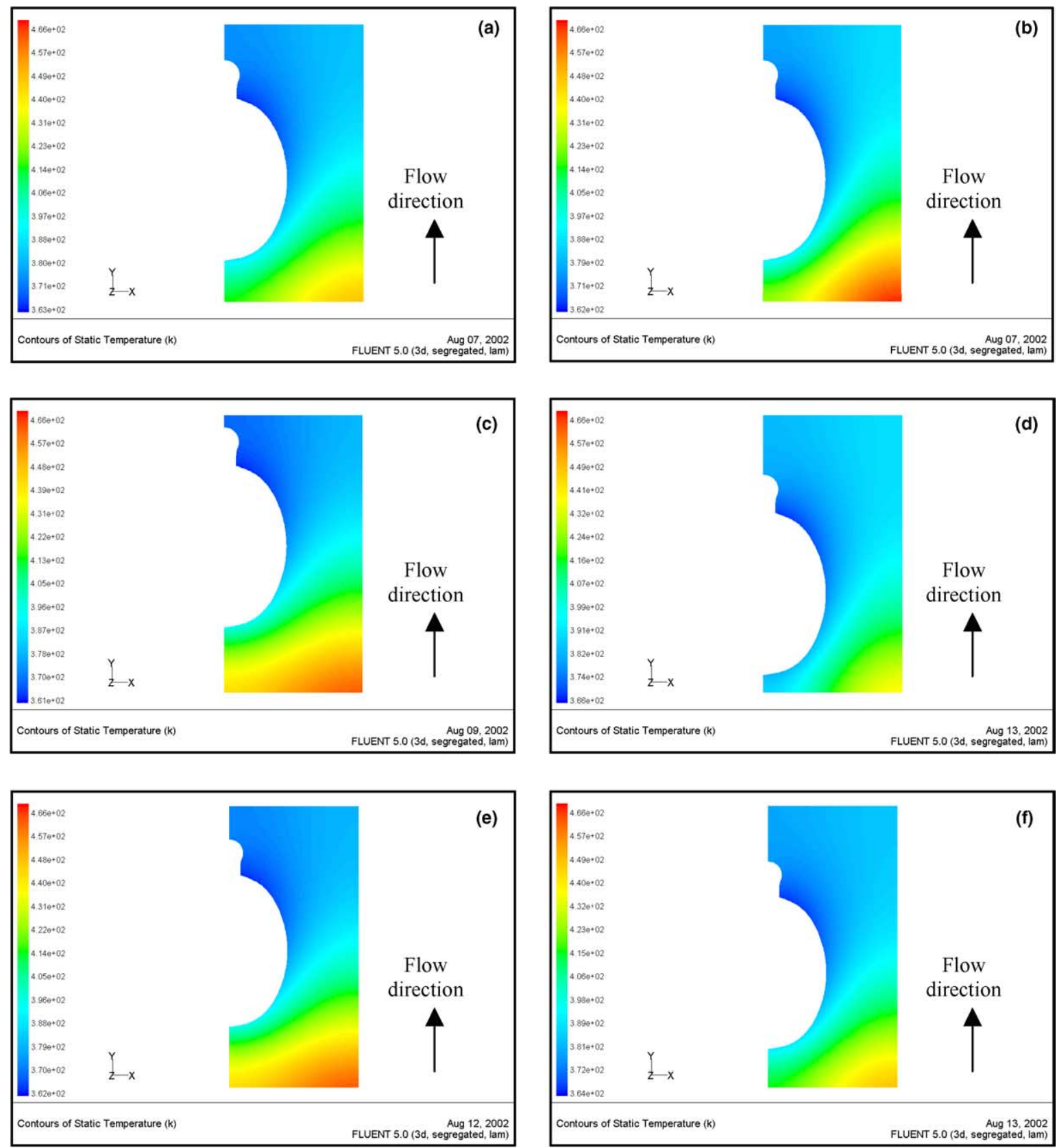

Fig. 4. Temperature distributions on the surface of the fins (each letter corresponds to its model type). 

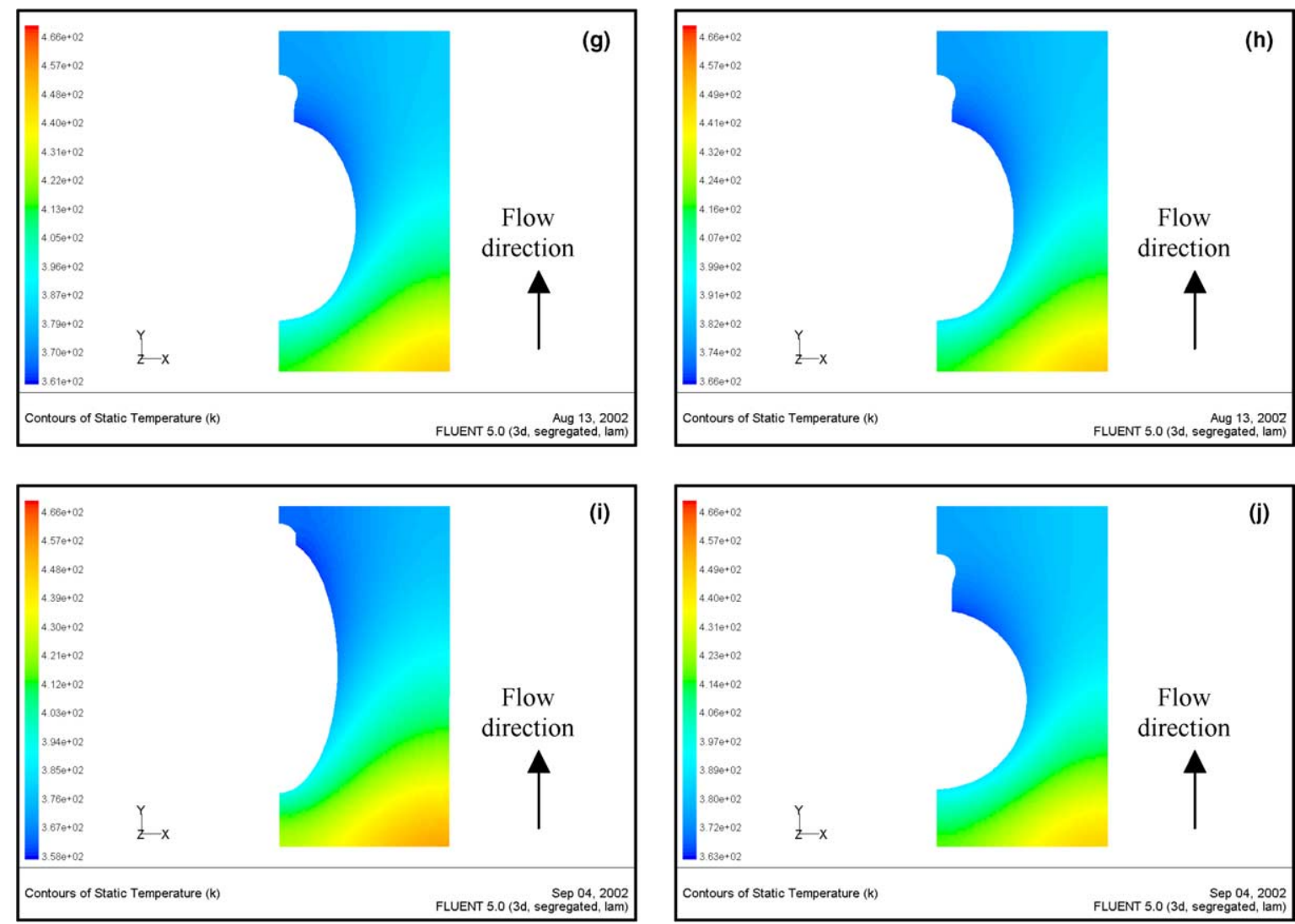

Fig. 4 (continued)

Free stream temperature is defined as boundary condition for the inner wall of fin tube. The middle section of fin is taken into consideration and free stream temperature is assumed as $343 \mathrm{~K}$. The material of fin and tube is assumed to be copper. The physical properties of copper are taken as constant, whereas the flue gas properties are taken as a function of temperature. The flow is assumed to be steady, incompressible and laminar because of the low Reynolds number of the flow.

\section{Numerical results}

The software is run for each model in order to obtain numerical results. Fig. 3 shows the dimensions taken into consideration as geometrical parameters.

Dimensions of the models, which are taken from commercially available products, are given in Table 1. Distance between the fins is $2.6 \mathrm{~mm}$, except for the Model (b) which has a $2.7 \mathrm{~mm}$ gap.

The temperature distributions on the surface of ten different fins are shown in Fig. 4. Flow velocity distributions at middle plane inside the gap domain are shown in Fig. 5, as well. 
The heat transferred from the flue gas passing through the gap between fins to the water flowing through the fin tube, the static and total pressure drop values of flue gas across the heat exchanger are also, obtained from the solution of the models and tabulated in Table 2. Since the transferred
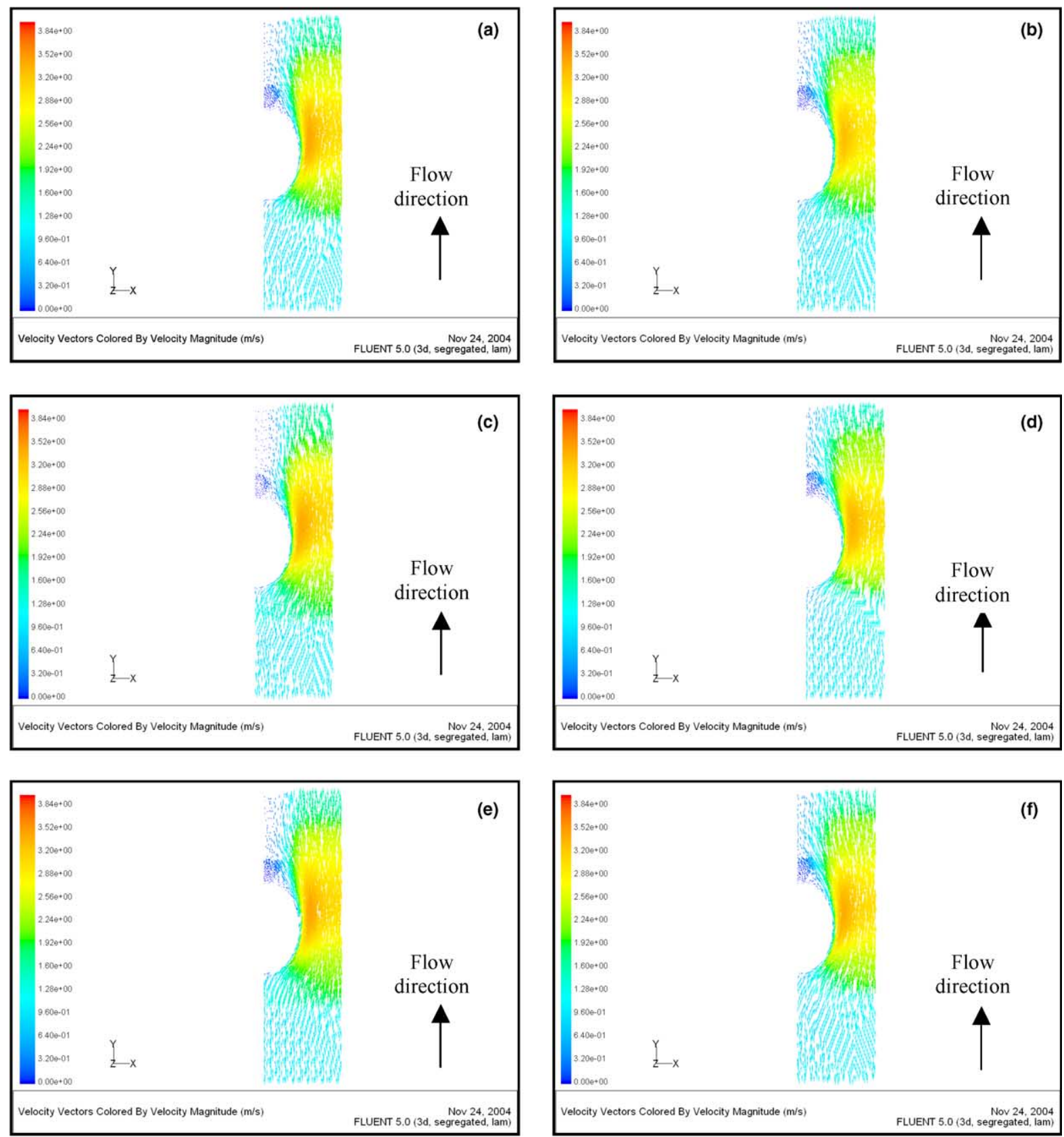

Fig. 5. Flow velocity distributions at middle plane inside the gap domain (each letter corresponds to its model type). 

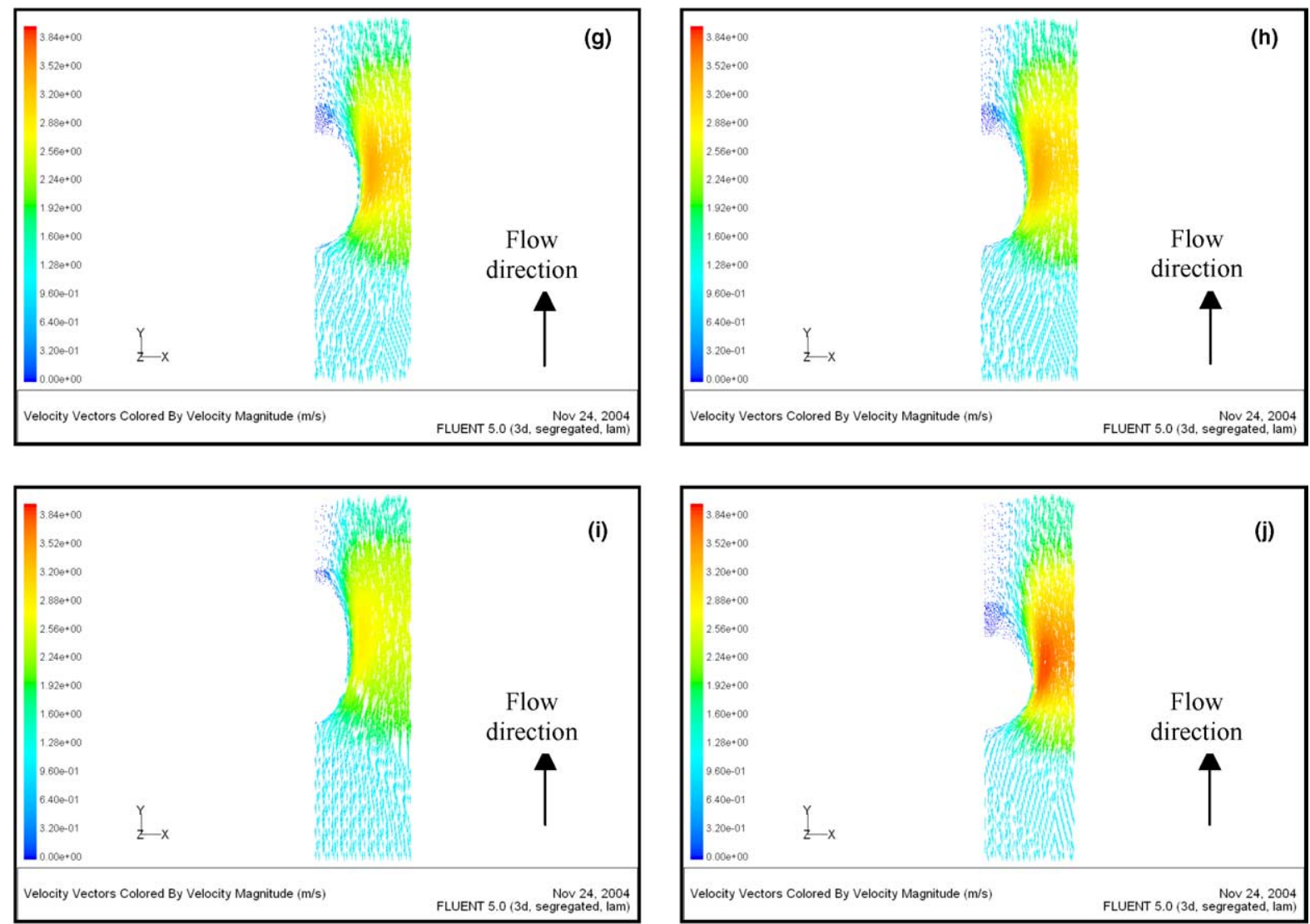

Fig. 5 (continued)

Table 2

Comparison of the models

\begin{tabular}{lllllllr}
\hline $\begin{array}{l}\text { Model } \\
\text { type }\end{array}$ & $\begin{array}{l}Q \text { (per segment) } \\
(\mathrm{W})\end{array}$ & $\begin{array}{l}Q \text { (per fin) } \\
\text { (W) }\end{array}$ & $\begin{array}{l}\text { Normalized } \\
Q(\%)\end{array}$ & $\begin{array}{l}\text { Static } \\
\text { pressure } \\
\text { drop (Pa) }\end{array}$ & $\begin{array}{l}\text { Normalized } \\
\text { static } \\
\text { pressure } \\
\text { drop (\%) }\end{array}$ & $\begin{array}{l}\text { Total } \\
\text { pressure } \\
\text { drop (Pa) }\end{array}$ & $\begin{array}{l}\text { Normalized } \\
\text { total pressure } \\
\text { drop (\%) }\end{array}$ \\
\hline $\mathrm{a}$ & 24.38377 & 243.8377 & 100 & 3.47341 & 100 & 3.43578 & 100 \\
$\mathrm{~b}$ & 23.83018 & 238.3018 & 97.729 & 3.16112 & 91.009 & 3.10451 & 90.358 \\
$\mathrm{c}$ & 24.51154 & 245.1154 & 100.524 & 3.50543 & 100.922 & 3.44119 & 100.157 \\
$\mathrm{~d}$ & 24.20525 & 242.0525 & 99.268 & 3.46761 & 99.833 & 3.44989 & 100.411 \\
$\mathrm{e}$ & 24.73531 & 247.3531 & 101.442 & 3.60119 & 103.679 & 3.55572 & 103.491 \\
$\mathrm{f}$ & 24.58990 & 245.8990 & 100.845 & 3.56374 & 102.601 & 3.54253 & 103.107 \\
$\mathrm{~g}$ & 24.41507 & 244.1507 & 100.128 & 3.47137 & 99.941 & 3.43359 & 99.936 \\
$\mathrm{~h}$ & 24.35337 & 243.5337 & 99.875 & 3.47537 & 100.056 & 3.43877 & 100.087 \\
$\mathrm{i}$ & 24.65000 & 246.5000 & 101.092 & 3.03291 & 87.318 & 2.99262 & 87.102 \\
$\mathrm{j}$ & 24.32834 & 243.2834 & 99.773 & 4.00500 & 115.305 & 3.93852 & 114.632 \\
\hline
\end{tabular}


heat is corresponding to one tenth segment of the fin, actual heat transfer from one fin, also, is indicated as heat transfer per fin. Normalized heat transfer, static, and total pressure drop values, given in Table 2, are calculated by taking the values of the Model (a) as $100 \%$. These normalized values make the comparison of the models easier.

\section{Discussion and conclusion}

The effects of fin tube center location, fin height, tube thickness, tube ellipticity, and distance between fins on heat transfer between flue gas and water, and pressure drop of flue gas passing through the fins are investigated, numerically. On the basis of previous results, the following discussions and conclusions are made:

- The distance between fins has an important effect on pressure drop. For the models with ellipticity value of 0.7345 , Model (b) has the smallest static and total pressure drops. Since flue gas velocity is decreased, the lower pressure drop value is obtained.

- Placement of the tube in downstream region, as in Model (c), increases the heat transfer between flue gas and water. The reason of this augmentation can be revealed as horseshoe vortex effect. If the fin tube is placed in the upstream region, heat transfer augmentation caused by horseshoe vortex could not be noticed at sufficient level. But, if it is placed in the downstream region which has lower Nusselt number, horseshoe vortex can be noticed strongly. In addition to this, recirculating vortices formed behind the tube attenuate negative effect on heat transfer when the fin tube is placed at the downstream region. This effect can be seen for the results of Models (e) and (f), as well.

- Greater heat transfer and pressure drop values are obtained as the fin height is increased, due to the increased heat transfer surface area.

- As the tube thickness is decreased, heat transfer is increased whereas pressure drop is decreased. Because heat resistance between water and flue gas is lower for this case.

- As ellipticity increases in a tube, the heat transferred across a heat exchanger increases. The ellipticity, also, affects pressure drop positively. This result can be revealed that as ellipticity increases, the cross section of flue gas flow, also, increases. Elliptical tube results in a lesser drag than the circular tube, due to its better aerodynamic shape. This shape causes better heat transfer characteristics, as well.

Although the present study has been completed for one row heat exchangers, the results can be applied to heat exchangers with more rows. The results concluded above are in good agreement with previous experimental and numerical studies. Finally, this entire study should have a great value for direct application to heat exchanger design aspect.

\section{References}

[1] D.G. Shepherd, Performance of one-row tube coils with thin-plate fins, low velocity forced convection, Heating, Piping Air Cond. 28 (1956) 137-144. 
[2] F. Schulemberg, Finned elliptical tubes and their applications in air-cooled heat exchangers, J. Eng. Ind. 88 (1966) 179-190.

[3] F.E.M. Saboya, E.M. Sparrow, Local and average transfer coefficients for one-row plate fin and tube heat exchanger configurations, J. Heat Transfer 96 (1974) 265-272.

[4] F.E.M. Saboya, E.M. Sparrow, Transfer characteristics of two-row plate fin and tube heat exchanger configurations, Int. J. Heat Mass Transfer 19 (1976) 41-49.

[5] F.E.M. Saboya, E.M. Sparrow, Experiments on a three-row fin and tube heat exchanger, J. Heat Transfer 98 (1976) 520-522.

[6] R.L. Webb, Air-side heat transfer in finned tube heat exchangers, Heat Transfer Eng. 1 (3) (1980) 33-49.

[7] E.C. Rosman, P. Carajilescov, F.E.M. Saboya, Performance of one and two-row tube and plate fin heat exchangers, J. Heat Transfer 106 (1984) 627-632.

[8] L.A.O. Rocha, F.E.M. Saboya, J.V.C. Vargas, A comparative study of elliptical and circular sections in one and two row tubes and plate fin heat exchangers, Int. J. Heat Fluid Flow 18 (1997) 247-252.

[9] B. Kundu, P.K. Das, Optimum dimensions of plate fins for fin-tube heat exchangers, Int. J. Heat Fluid Flow 18 (1997) $530-537$.

[10] M. Abu Madi, R.A. Johns, M.R. Heikal, Performance characteristics correlation for round tube and plate finned heat exchangers, Int. J. Refrig. 21 (7) (1998) 507-517.

[11] R. Romero-Méndez, M. Sen, K.T. Yang, R. McClain, Effect of fin spacing on convection in a plate fin and tube heat exchanger, Int. J. Heat Mass Transfer 43 (2000) 39-51.

[12] C.C. Wang, K.Y. Chi, Heat transfer and friction characteristics of plain fin-and-tube heat exchangers, part I: new experimental data, Int. J. Heat Mass Transfer 43 (2000) 2681-2691.

[13] C.C. Wang, K.Y. Chi, C.J. Chang, Heat transfer and friction characteristics of plain fin-and-tube heat exchangers, part II: Correlation, Int. J. Heat Mass Transfer 43 (2000) 2693-2700.

[14] S.M. Saboya, F.E.M. Saboya, Experiments on elliptic sections in one and two row arrangements of plate fin and tube heat exchangers, Exp. Therm. Fluid Sci. 24 (2001) 67-75.

[15] J.Y. Kim, T.H. Song, Microscopic phenomena and macroscopic evaluation of heat transfer from plate fins/circular tube assembly using naphthalene sublimation technique, Int. J. Heat Mass Transfer 45 (2002) 3397-3404.

[16] K. Torikoshi, G. Xi, Y. Nakazawa, H. Asano, Flow and heat transfer performance of a plate fin and tube heat exchanger (1st report: effect of fin pitch), in: 10th Int. Heat Transfer Conf. 1994, paper 9-HE-16, 1994, pp. 411-416.

[17] S. Kakaç, Y. Yener, Convective Heat Transfer, second ed., CRC Press Begell House, Boca Raton, Florida, 1995, pp. 279-309. 